\title{
Quantification of Pseudocercospora fuligena in Tomato Lines Carrying Introgressions from Solanum habrochaites Using a qPCR Assay
}

Marc Zahn, Felix Teuber, Katharina Bollig, and Walter Johannes Horst, Institute for Plant Nutrition, Faculty of Natural Sciences, Leibniz University Hannover, 30419 Hannover, Germany

\begin{abstract}
Zahn, M., Teuber, F., Bollig, K., and Horst, W. J. 2011. Quantification of Pseudocercospora fuligena in tomato lines carrying introgressions from Solanum habrochaites using a qPCR assay. Plant Dis. 95:394-400.

Black leaf mold (BLM), caused by Pseudocercospora fuligena, is a major plant growth- and yield-limiting factor for tomato production in the humid tropics. A library of 90 introgession lines (ILs), the BLMresistant donor Solanum habrochaites, and the BLM-susceptible recurrent $S$. lycopersicum parent (RP) were visually phenotyped under natural infection conditions in a nethouse in central Thailand. ILs showing no and severe BLM symptoms were among the phenotypes. Because visually classifying different phenotypes of BLM symptoms can lead to erroneous results due to the similarity of BLM symptoms to other abiotic and biotic problems, a SYBR Green-based quantitative polymerase chain reaction (qPCR) assay for fungal DNA was developed. Correlation of the results from visual phenotyping of plants grown in

Thailand under natural infection conditions with qPCR test-based quantities of the tomato leaf fungal DNA content, while significant, explained only $39 \%$ of the relationship across the library population. Based on this phenotyping in Thailand, selected ILs were artificially infected in a growth chamber in Germany with a $P$. fuligena isolate from Thailand. The results of the natural infection could be verified for the selected ILs in the growth-chamber experiment. A close correlation $\left(R^{2}=0.87\right)$ existed between the visual disease rating and fungal DNA content in leaves in the latter experiment. Three lines without visual symptoms and very low amounts of $P$. fuligena-specific rDNA shared an overlapping introgression on chromosome one that may be associated with BLM resistance.
\end{abstract}

Tomato black leaf mold (BLM), caused by the fungus Pseudocercospora fuligena, is widespread in the humid tropics (36). The fungus belongs to the teleomorphic genus Mycosphaerella, an Ascomycete. The disease and the pathogen were first observed and described in the Philippines in 1938 (36) but have also been reported to occur in Cambodia, India, Ivory Coast, Japan, Malaysia, Taiwan, Thailand, the Solomon Islands, and Florida (United States) (16). Hartman et al. (16) indicated that BLM develops under conditions of warm temperatures $\left(28\right.$ to $\left.30^{\circ} \mathrm{C}\right)$, high relative humidity (90 to $95 \%$ ), and long periods of leaf wetness, conditions which are typical for the humid tropics and protected cultivation in tropical and subtropical climates. The presence of moisture on the foliage from dew, rainfall, and fog provides favorable conditions for infection. Combating the fungus is difficult and presently only possible through the application of fungicides $(17,18)$. Therefore, there is a need to develop tomato cultivars with increased resistance against BLM.

Tomato (Solanum lycopersicum) is the second most consumed vegetable worldwide (FAOSTAT 2005; http://faostat.fao.org) and is well studied in terms of genetics, genomics, cultivation, and breeding (1). In addition, tomato is an important model organism for crops because the quantity of available genomic information for tomato is constantly growing. The Sol Genomics Network (http://solgenomics.net) provides important information for species in the Solanaceae family (e.g., tomato, potato, eggplant, pepper, and petunia). Presently, about $48 \%$ of the tomato genome has been sequenced (http://www.sgn.cornell.edu/about/tomato_sequencing.pl) and many expressed sequence tag clones are available. Additionally, this resource provides genetic and physical maps. Several sets of introgession lines (ILs) are available from tomato. An IL ideally contains a single, defined chromosome segment from a

Corresponding author: W. J. Horst, E-mail: horst@pflern.uni-hannover.de

Accepted for publication 27 November 2010.

doi:10.1094/PDIS-07-10-0487

(C) 2011 The American Phytopathological Society donor species in a uniform genetic background (46). IL libraries containing the whole or predominant parts of the genome of the donor species can be used for the identification of quantitative trait loci (QTLs) and for comparative transcriptiomic and metabolomic analysis because phenotypic variation between the lines and the recurrent parent (RP) is, in general, directly associated with the introgressed chromosome segment (3). Tomato ILs are available from S. pennellii LA716 (12), S. habrochaites LA1777 (28), S. habrochaites LA407 (13), and S. lycopersicoides LA2951 (9). The use of exotic donors for the generation of IL populations opens the possibility to widen the genetic background for tomato and discover new resistance genes $(12,46)$. The use in this study of an IL population utilizing $S$. habrochaites as a donor was essential for this study because of the described resistance of this wild species against $P$. fuligena (43).

Visual phenotyping of disease symptoms caused by fungi is widely done but lacks objective or quantitative criteria $(6,32$ 34,40 ), may be biased by symptoms of additional biotic and abiotic stresses, and does not allow conclusions on the effective accumulation of the fungus in the plant tissue (tolerance or partial tolerance). For this purpose, it was necessary to develop a quantitative real-time polymerase chain reaction (qPCR) assay. qPCR-based methods are an appropriate tool for the speciesspecific detection and quantification of fungi in plant material (26). This assay was based on primers which amplify highly variable fungal internal transcribed spacer (ITS) sequences of the fungal ribosomal DNA (rDNA). The high variability of these sequences can be used to distinguish between different fungal species or even pathovars (45). Primers specifically surrounding the $5.8 \mathrm{~S}$ rRNA-encoding sequence and, therefore, located between the small subunit-coding sequence (SSU) and the large subunit-coding sequence (LSU) of the ribosomal operon are used for this purpose (26).

The objective of this study was to develop a qPCR assay based on ITS sequences for species-specific detection and quantification of $P$. fuligena in tomato leaves. A sensitive qPCR assay may be useful as an alternative approach to visual phenotyping of BLM symptoms in screening tomato for BLM resistance. 


\section{Materials and Methods}

Biological materials. In searching for genetic variability in BLM resistance, the IL library of Monforte and Tanksley received from the Tomato Genetics Resource Center, Davis, CA (http://tgrc.ucdavis.edu/) was used. The seeds received for phenotyping in Thailand were first multiplied by selfing under glasshouse condition in Hannover, Germany in 2007, and also used in preliminary studies. The rDNA sequence of the $P$. fuligena isolate was used for the primer development. The fungus was isolated from infected leaves at the Asian Institute of Technology (AIT) in Thailand and characterized at the Institute of Plant Diseases and Plant Protection, Leibniz University, Hannover, Germany (2). The isolate used from a tropical origin did not sporulate in in vitro culture and sporulated weakly in growth-chamber experiments in Hannover, Germany. Several media, temperatures, and light intensities were tested. Other isolates from subtropical origins are able to sporulate in culture (P. Hanson, World Vegetable Center, personal information). In addition to $P$. fuligena, different tomato pathogens were cultivated as specificity controls during testing of the qPCR test developed for $P$. fuligena. Sources of isolates along with plant accessions are indicated in Table 1. All fungi were cultivated on potato dextrose agar (PDA) in 9-cm-diameter petri dishes inside a climate chamber set at $21^{\circ} \mathrm{C}$ with 12 -h day and night periods.

Visual phenotyping. The $90 \mathrm{ILs}$, the donor (S. habrochaites, LA1777), and the RP (S. lycopersicum, LA4024) were cultivated in naturally and mechanically ventilated nethouses in central Thailand at the AIT. For a more detailed description of the experimental site and the cultivation technology, see Max et al. (27). For the preliminary phenotyping in 2007, three to five individual plants of each line and the parents were screened for BLM resistance in a nonrandomized design in one nethouse. The availability of multiplied seeds allowed a more detailed phenotyping in 2008. Therefore, only the results of 2008, consisting of 10 replications for each line, are presented here (920 plants). The experimental design had a nested randomization structure with blocks nested within the greenhouses, while the lines of interest were randomly arranged in each of the complete blocks. The experiment was conducted in two nethouses containing three-block replications and one additional nethouse containing four-block replications $(n=10)$. In preliminary experiments, this environment proved conducive for natural infections by $P$. fuligena. After preculture for 14 days in peat moss, the seedlings were transferred into 30 -cm-diameter pots with a commercial Thai potting mix and fertilized with $1 \%$ of a local fertilizer once a week. The BLM intensity was measured weekly for 12 weeks in the rainy season in August and September 2008. BLM phenotyping was done using the rating scheme for infected tomato leaves (4). To standardize visual phenotyping, computer-generated masters of tomato leaves with different infection levels were generated. The rating was performed for different plant heights ( 0 to $0.5 \mathrm{~m}, 0.5$ to $1 \mathrm{~m}, 1$ to $1.5 \mathrm{~m}$, and 1.5 to $2 \mathrm{~m}$ ), and two leaves from each plant height and replication were rated. Some lines did not grow higher than $0.5 \mathrm{~m}$; therefore, data presented here represent the level of infection after 9 weeks of cultivation in nethouses at a plant height of 0 to $0.5 \mathrm{~m}$. At this time, a very clear discrimination between susceptible and resistant lines was possible because resistant lines did not develop distinct necrotic areas, particularly on older leaves. For the qPCR analysis, one representative leaf of all ILs from one replication and, additionally, three leaves from the RP (S. lycopersicum LA4024), the donor, and a resistant line (LA3999) were harvested at this time point (Fig. 1A and B).

Based on the results of the phenotyping, under natural infection, conditions the RP, the donor, and three highly resistant (LA3919, LA3999, and LA3920), two medium-resistant (LA3928 and LA3932), and the most susceptible (LA3940) line were used to verify the results of the nethouse experiments in Thailand under controlled environmental conditions in Hannover, Germany. An inoculation experiment was conducted in a greenhouse chamber under natural light at $80 \%$ humidity and $30^{\circ} \mathrm{C}$. Each line comprised four replicates within a completely randomized block. The plants were grown in 5-liter pots (one plant per pot) filled with substrate (Einheitserde P; Balster Einheitserdewerk GmbH, Germany) and fertilized once a week with $1 \%$ Flory 3 Mega (Euflor, Germany). After 4 weeks of cultivation in the climate chamber, the plants were inoculated. Because the P. fuliginea (sp.) isolate was not sporulating in culture, in spite of attempting different media, light, and temperatures, a mycelia-based inoculation technique was developed. The inoculum was generated by scraping mycelium from 4-week-old cultures of $P$. fuligena (Table 1) growing on PDA (as above) into $10 \mathrm{ml}$ of a $2 \%$ biomalt solution. The mycelium of 7 petri dishes was harvested and homogenized using an Ultra-Turrax TP18/10 (IKA-Werke GmbH \& CO, Germany). The suspension was filtered through cheesecloth and the volume was adjusted to $800 \mathrm{ml}$ with biomalt solution. Each tomato line was spray inoculated by eight spraying impulses $(8 \mathrm{ml})$ from a spray gun. During the inoculation, the spray gun was continuously shaken to prevent sedimentation of inoculum. The inoculum solution was microscopically examined after passing the spray gun. The average mycelium size was 50 to $150 \mu \mathrm{m}$ and $2^{5}$ fragments per milliliter. The leaves were phenotyped and harvested for DNA isolation after 6 weeks (Fig. 1C). Leaves were sealed in plastic bags and frozen at $-20^{\circ} \mathrm{C}$ until DNA isolation.

DNA extraction from fungi and plants. Whole leaves were homogenized under liquid nitrogen and DNA was extracted using a modified cetyltrimethylammonium bromide (CTAB) method (30). A 200-mg subsample and $50 \mathrm{mg}$ of grinded fungal mycelia were mixed with $1 \mathrm{ml}$ of CTAB buffer $(200 \mathrm{mM}$ Tris-HCL, $20 \mathrm{mM}$ EDTA, 2\% [wt/vol] CTAB, $1.4 \mathrm{M} \mathrm{NaCl}, 1 \%$ [wt/vol] polyvinylpyrrolidone, and $280 \mathrm{mM}$ mercaptoethanol, $\mathrm{pH} 8.0$, set with $\mathrm{NaOH}$ ). After an initial incubation period of $10 \mathrm{~min}$ at $42^{\circ} \mathrm{C}$ and a second incubation for $60 \mathrm{~min}$ at $65^{\circ} \mathrm{C}, 4 \mathrm{ml}$ of chloroform-isoamyl alcohol (24:1) was added. Samples were incubated on ice for $10 \mathrm{~min}$ and centrifuged for $15 \mathrm{~min}$ at $10,000 \times g$ and $4^{\circ} \mathrm{C}$. Then, $600 \mu \mathrm{l}$ of the upper aqueous phase was incubated with $5 \mu$ l of RNase A solution $(10 \mathrm{mg} / \mathrm{ml})$ for $20 \mathrm{~min}$ at $37^{\circ} \mathrm{C}$ to eliminate RNA before DNA precipitation. The integrity of the DNA was determined on $1 \%$ agarose gels and quantified using a nanophotometer ( $\mu$ Quant; BioTek Instruments, Munich).

Cloning of ITS from $P$. fuligena. The PCR amplification (BioRad CFX96; Bio-Rad Laboratories, Hercules, CA) of the ITS of $P$. fuligena was carried out in a $25-\mu$ l reaction mixture $(0.6 \mathrm{U}$ of Taq polymerase, $10 \times$ PCR buffer, and $0.1 \mathrm{mM}$ each dNTP; Fermentas, St. Leon-Rot, Germany) with $25 \mathrm{ng}$ of genomic DNA from $P$. fuligena and $0.25 \mu \mathrm{M}$ primers ITS4 (TCC TCC GCT TAT TGA TAT GC) and ITS5 (GGA AGT AAA AGT CGT AAC AAG G), as described by White et al. (45). The cycling conditions included an initial denaturation of $3 \mathrm{~min}$ at $94^{\circ} \mathrm{C}$; followed by 30 cycles of $94^{\circ} \mathrm{C}$ for $15 \mathrm{~s}, 60^{\circ} \mathrm{C}$ for $30 \mathrm{~s}$, and $72^{\circ} \mathrm{C}$ for $30 \mathrm{~s}$; and a final elongation for $7 \mathrm{~min}$ at $72^{\circ} \mathrm{C}$. The 567 -bp fragment was cloned into the pGEM T Easy vector system (Promega Corp., Madison, WI) according to the instructions of the manufacturer and transformed into competent Escherichia coli XL-2 Blue cells (19). Bidirectional

Table 1. Fungal isolates used for the calibration and evaluation of the quantitative polymerase chain reaction assay

\begin{tabular}{lllc}
\hline Genus, species & \multicolumn{1}{c}{ Host } & Isolate code & Origin $^{\mathbf{b}}$ \\
\hline Alternaria alternata & Beta vulgaris & DSM 62006 & 1 \\
Alternaria solani & Tomato & DSM 2947 & 1 \\
Aspergillus niger & Soil & DSM 2182 & 1 \\
Botrytis cinerea & Tomato & DSM 877 & 1 \\
Pseudocercospora fuligena & Tomato & na & 2 \\
Verticillium dahliae & Tomato & na & 3 \\
\hline
\end{tabular}

a Abbreviation: na = isolate code not available.

b 1, German Resource Centre for Biological Material, Braunschweig, Germany; 2, isolate from Bernhard Hau, Institute of Plant Diseases and Plant Protection, Hannover, Germany, isolated at the Asian Institute of Technology, Pathumthani, Thailand; 3, isolate from Institut für Gemueseund Zierpflanzenbau, Grossbeeren, Germany. 
sequencing of three independent clones was carried out by ITT Biotech (Bielefeld, Germany). The cloned sequence was submitted to GenBank (GU060636).

qPCR primer design. The cloned and sequenced ITS from $P$. fuligena was integrated into a sequence alignment with ITS regions of other fungal pathogens of tomato. The AlignX software from Vector NTI Advanced 10 (Invitrogen Corp. San Diego, CA) was used to generate an alignment by the use of the following ITS regions: Alternaria alternata (AF347031), A. solani (AY154715, EU315064, and U80204), Botrytis cinerea (Z73764), Fusarium oxysporum (AB369259 and AF069310), Phytophthora infestans (EF126351), Verticillium albo-atrum (AB353342, AY555955, DQ825979, and X60705), and V. dahliae Isolate IGZ (GU060637). Pseudocercospora fuligena-specific primers were developed using the software Primer3 (37). Primer pairs surrounding the $5.8 \mathrm{~S}$ rRNA-encoding sequence of $P$. fuligena were located between ITS1 and ITS2 of the ribosomal operon, or they were positioned to amplify sequences into the ITS1 or ITS2 regions. Three primer pairs were designed: ITS1 amplifying 70 bp (GCG CGC CTT AAA GTC TTC/CTC CGA AGC GAA TTG AAA AA), ITS2 amplifying $110 \mathrm{bp}$ (CCC TTT GTG AAC CAA ACT TGT/TGT TTA AAC TCC GAC GCA AA), and qITSpf amplifying 342 bp (CCG GAG GGC TTC TAA ACA C/TTT TCA ATT CGC TTC GGA GT).

PCR amplification from plant leaves. The qPCR assays on fungal DNA were performed with the StepOnePlus Real-Time PCR System (Applied Biosystems, Carlsbad, CA). Each assay was repeated three times, including triplicate technical replications. Data sets were analyzed using the StepOnePlus Software v2.0 according to the manufacturer's instructions. DNA was diluted to a

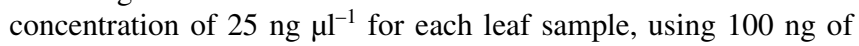
DNA in each qPCR reaction mixture with the following conditions: the 25- $\mu$ l reaction mixture comprised $0.6 \mathrm{U}$ of Taq Hotstart Polymerase (Fermentas, St. Leon-Roth, Germany), 1× PCR buffer without $\mathrm{MgCl}_{2}$ (Fermentas), $0.2 \mathrm{mM}$ each dNTP (Fermentas), 0.5 $\mathrm{mM}$ ROX (Invitrogen $\mathrm{GmbH}$, Darmstadt, Germany), $3.6 \mathrm{mM}$ $\mathrm{MgCl}_{2}$ (Fermentas), $0.25 \mu \mathrm{M}$ each primer, and a $10^{-5}$ dilution of SYBR Green I solution (Invitrogen $\mathrm{GmbH}$ ). The conventional PCR program comprised an initial denaturation at $94^{\circ} \mathrm{C}$ for $7 \mathrm{~min}$ followed by 33 cycles of $94^{\circ} \mathrm{C}$ for $15 \mathrm{~s}, 60^{\circ} \mathrm{C}$ for $30 \mathrm{~s}$, and $72^{\circ} \mathrm{C}$ for $15 \mathrm{~s}$. The qPCR program consisted of an initial denaturation at $94^{\circ} \mathrm{C}$ for $7 \mathrm{~min}$ followed by 40 cycles of $94^{\circ} \mathrm{C}$ for $15 \mathrm{~s}, 60^{\circ} \mathrm{C}$ for 30 $\mathrm{s}$, and $72^{\circ} \mathrm{C}$ for $30 \mathrm{~s}$. After amplification, analyses of the melting curves were performed by heating the samples to $95^{\circ} \mathrm{C}$ for $15 \mathrm{~s}$ and cooling down to $55^{\circ} \mathrm{C}$ for $1 \mathrm{~min}$, followed by a gradual increase of the temperature to $95^{\circ} \mathrm{C}$.

Tests of qPCR specificity. The specificity and efficiency of primers was evaluated in four initial tests. (i) The ITS primers were tested for amplification of specific fragment sizes and the lack of primer dimers or multiple fragments. (ii) The efficiency of each primer pair was estimated by a standard curve method using a dilu- tion series of $0.006,0.032,0.16,0.8,4$, and $20 \mu \mathrm{g}$, with three technical replications. Dilution points containing less than $0.006 \mu \mathrm{g}$ were not used because of low reproducibility. The regression line equation and the corresponding $R^{2}$ value were calculated by the StepOnePlus Software v2.0 (Applied Biosystems; 4). The effect of tomato DNA on qPCR was tested by repeating standard curves with purified pathogen DNA mixed with different amounts of purified tomato DNA $(0,10$, or $25 \mathrm{ng})$. Correlations of the results obtained with the different concentrations of the $P$. fuligena dilution series with and without the tomato DNA were calculated according to Pearson (5). Cross-reactions of $P$. fuligena ITS primers with other fungal DNAs were investigated by the use of DNA from the fungal isolates described in Table 1 . For calculation of cross contamination, a given DNA amount $(20 \mathrm{ng})$ of each isolate was measured against a dilution series of $P$. fuligena DNA. The detected amount of fungal pathogen controls was calculated as percentage from the used total DNA amount.

Statistical analysis. Proc mixed (24) in SAS (version 9.1; SAS Institute, Cary, NC) was applied for statistical analyses. BLM severity ratings from the natural infection experiment were transformed with the $\arcsin (\operatorname{sqrt}(\mathrm{p}))$ function to correct for unbalanced variation among lines. Data were fitted to a mixed model, with ILs as fixed effects and greenhouses and blocks nested within greenhouses as random effects (35). Subsequently, pairwise comparisons among all lines were performed using Tukey's adjustment for multiple comparisons.

Based on BLM data, ILs were divided into five subgroups (A to E). The qPCR values were log transformed to achieve homogeneity of variances. The Wilcoxon rank-sum test was applied to analyze the correlation between the groups. Correlations were calculated using the R statistical package (R Development Core Team, Open Source) as a product-moment correlation according to Pearson. BLM rating and qPCR data obtained during the growth-chamber experiments showed a balanced variation, and the correlation was calculated using the $\mathrm{R}$ statistical package.

\section{Results}

Visual assessment of the BLM symptoms. The IL library of Monforte and Tanksley (28) was preliminarily visually phenotyped in 2007 and, subsequently, in a more detailed and replicated approach in 2008 for BLM resistance under natural infection conditions in Thailand (Fig. 2), and a subpopulation of eight ILs was phenotyped in a growth chamber after artificial inoculation. According to the rating of the BLM symptoms (4), the total population could be separated into five susceptibility groups (A to E). Due to the lack of normality, a Wilcoxon rank-sum test was performed (21) with an $\alpha$ value of 5\%. The $P$ value was corrected following Bonferroni (11). A significant difference between the highly susceptible groups A and B $(P$ value $=0.0452)$ and the intermediate susceptible group D and resistant group E $(P$ value $=0.0261)$ could be detected. The values of the intermediate resistant and susceptible
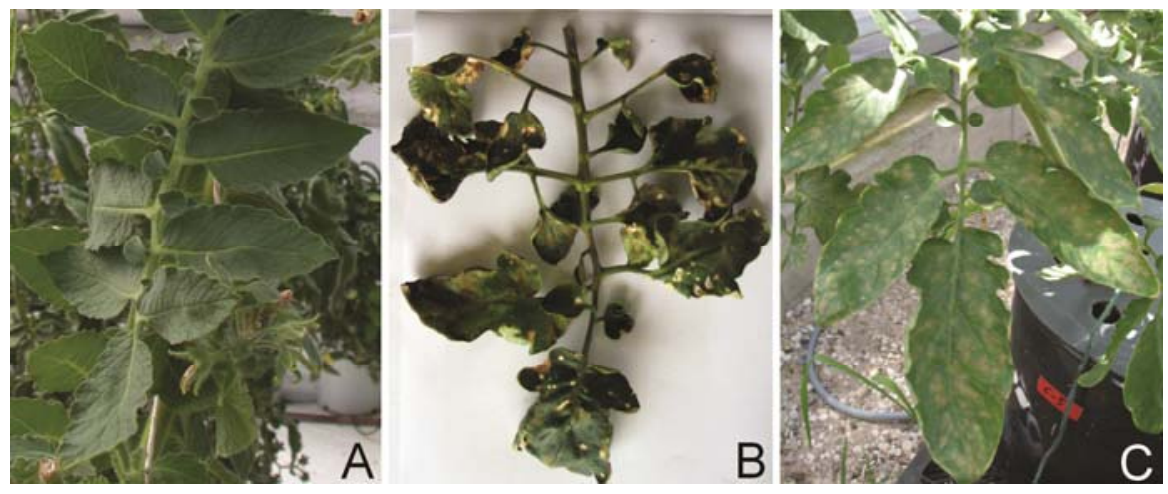

Fig. 1. Host reactions of the recurrent parent (RP) Solanum lycopersicum (LA4024) and the donor S. habrochaites (LA1777) after inoculation with Pseudocercospora fuligena in growth chambers in Hannover, Germany and a nethouse in central Thailand. Reactions of A, the S. habrochaites donor and B, the RP (LA4024) 9 weeks after cultivation in nethouses at the Asian Institute of Technology in central Thailand. C, Reactions of the RP (LA4024) 6 weeks after inoculation in a growth chamber in Hannover, Germany. 
groups (B, C, and D) were not significantly different from each other. The S. habrochaites donor (LA1777) was among the most resistant lines (group E), showing no BLM symptoms. The $S$. lycopersicum RP (LA 4024) was classified as medium susceptible. Thus, the population showed a transgressive segregation. Many ILs developed a higher susceptibility than the RP (Fig. 2).

From the IL population,we selected eight ILs representing the resistant group (LA3919, LA3999, and LA3920), two lines show- ing very mild symptoms (LA3928 and LA3932), a highly susceptible line (LA3940), the donor (LA1777), and the RP (LA4024). The rating of the disease symptoms and DNA amounts corroborate the rating from the nethouse experiments in Thailand (Fig. 3B): the donor and three lines (LA3919, LA3999, and LA3920) did not develop any BLM symptoms, two lines developed much milder symptoms (LA3928 and LA3932) than the RP, and the highly susceptible line (LA3940) showed much more serve BLM symptoms than the RP.

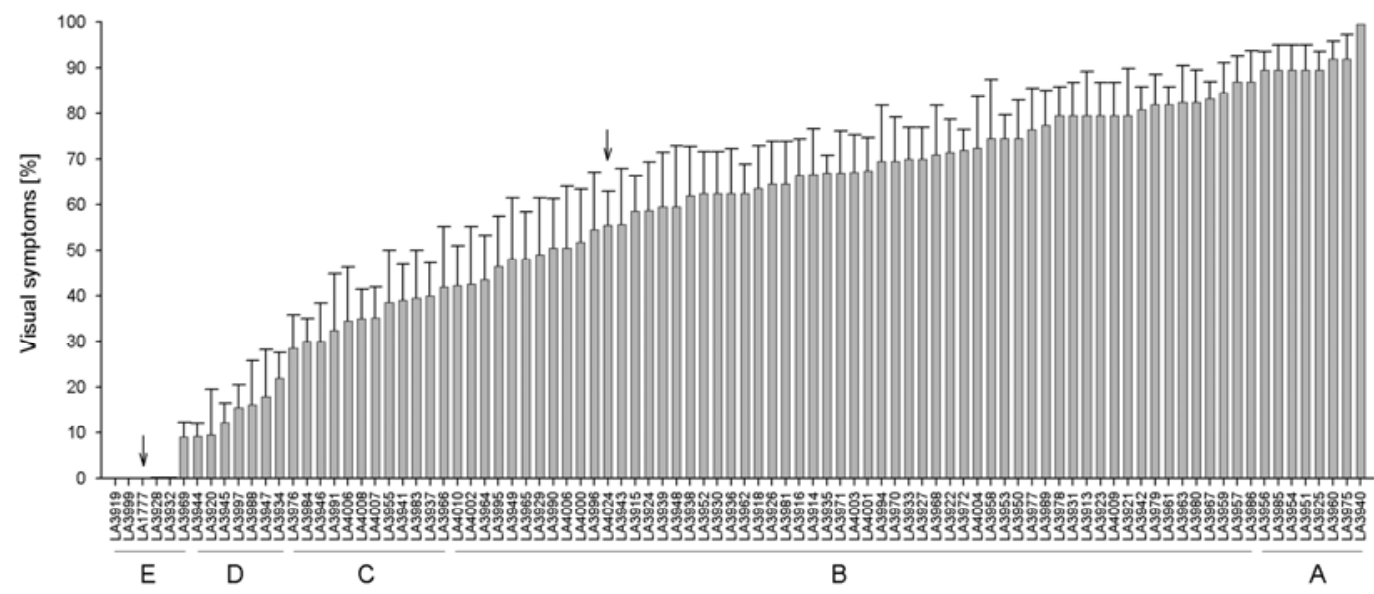

Fig. 2. Mean rating of 90 introgession lines (ILs), the Solanum lycopersicum recurrent parent (RP) and the $S$. habrochaites donor after natural infection with Pseudocercospora fuligena in a nethouse experiment in central Thailand in 2008. For statistical analysis, a stabilization of variances was performed by using an $\arcsin (\mathrm{sqrt}(\mathrm{p}))$ function. ILs within the group $\mathrm{A}, \mathrm{B}, \mathrm{C}$, and $\mathrm{D}$ have a significantly lower resistance or tolerance against $P$. fuligena than the donor in group $\mathrm{E}$. Group $\mathrm{E}$ contains the resistant donor and four highly resistant or tolerant ILs. Donor (LA1777) and RP (LA4024) are marked with arrows. ILs are grouped according to their level of infection. Bars represent means \pm standard errors of $n=10$ replicates.

A

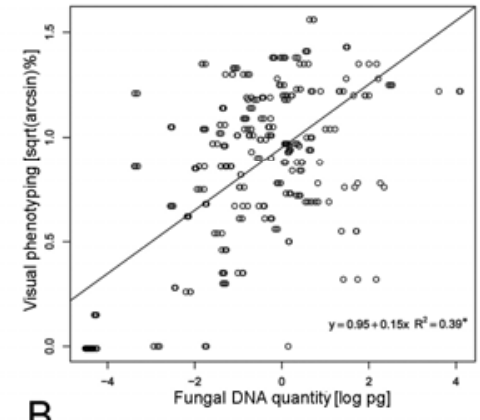

B

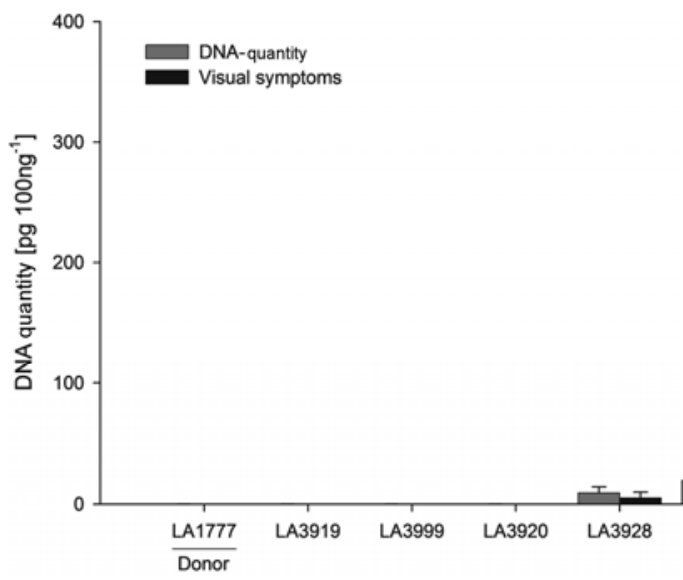

C

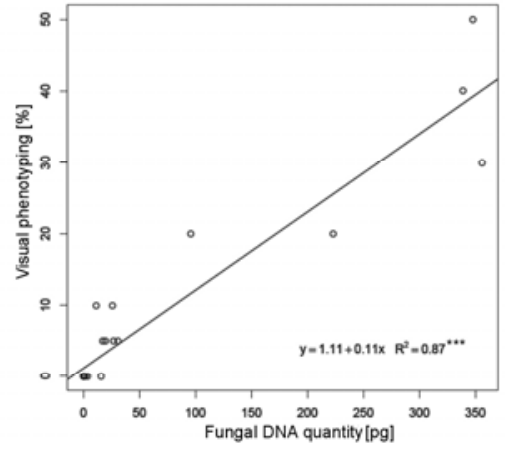

100

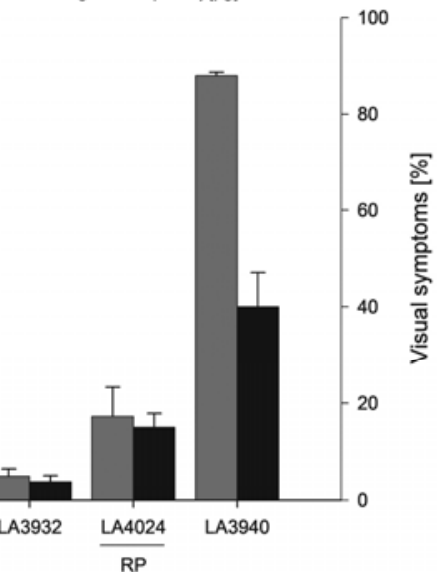

Fig. 3. Correlation between visual symptoms of black leaf mold and the quantity of DNA detected from Pseudocercospora fuligena. A, Pearson product-moment correlation between visual phenotyping and detected fungal DNA after natural infection experiments in nethouses in Thailand. Logarithms of detected fungal DNA amounts were calculated as nanograms in $100 \mathrm{ng}$ of total plant DNA. Percent values of the visual phenotyping were transformed using a sqrt(arcsin) transformation. The regression line equation and the $R^{2}$ value are displayed; * denotes probability level at $P<0.05$. B, Comparison of visual phenotyping and $P$. fuligena DNA amount determined by a qPCR assay for eight selected lines after inoculation in growth chambers of the $S$. habrochaites donor (LA1777) and the S. lycopersicum (LA4024) recurrent parent (RP). Black bars represent the visual symptoms; gray bars represent the DNA amount. Bars indicate \pm standard error, $n=4$ for the DNA amount and visual rating. C, Correlation between visual phenotyping and detected fungal DNA amount after inoculation in growth chambers. DNA amounts were calculated as picograms in $100 \mathrm{ng}$ of total plant DNA. The regression line equation and the $R^{2}$ value are displayed; ${ }^{* *}$ denotes levels of significance at $P<0.001$. 
Development of a qPCR assay for $\boldsymbol{P}$. fuligena. The ITS region of $P$. fuligena was not available when this research was initiated. Thus, specific primers were designed for the ITS of $P$. fuligena isolated at the experimental site in Thailand. Based on the primer pair of White et al. (45), sequence-specific primers were designed for the amplification of the ITS of P. fuligena. ITS regions from typically tomato-infecting fungi (R. Grosch, IGZ, Germany, personal information) were aligned in combination with the ITS of $P$. fuligena. Nonconserved areas in the ITS1 and ITS2 regions were chosen to create discriminating primer pairs. Three primer pairs were designed using the Primer 3 software (37). Primers were tested for possible formation of dimers or unspecific PCR fragment sizes with a conventional PCR using the same reaction mixture and cycling conditions as for the qPCR (Fig. 4A). All primer pairs produced PCR fragments of the predicted size and no dimers were formed under the given conditions. ITS2 showed a weak amplification but created a PCR fragment with the predicted size. The efficiency of amplification was checked by a standard curve method (Fig. 4B). The primer pairs qITSpf and ITS1 had efficiencies of 93 and $91 \%$, respectively. To examine the interference of plant DNA on the standard curve dilutions of fungal DNA, dilutions of fungal DNA were mixed with pure tomato DNA from infection-free plants. The correlation of fungal DNA with and without plant DNA was determined for the primer pair qITSpf, with $r=0.99$ for all steps of the dilution series. The cross-reactions of the primer pair qITSpf with other tomato fungal pathogens were tested with genomic DNA of these fungi (Fig. 4C). The primer pair ITS2 showed cross-reactions with all fungi. The primer pairs qITSpf and ITS1 shared similar levels of cross-reactions with other fungal DNA $(0.001$ to $0.03 \%)$. The detection of fungal rDNA from $A$. solani and $A$. alternata using the primer pair qITSpf could be differentiated from a $P$. fuligena-specific PCR fragment using a melting curve analysis. A. alternata DNA produced multiple peaks with a clearly lower Tm value than $P$. fuligena-specific PCR fragments (Tm $84.4^{\circ} \mathrm{C}$ ). The rDNA detected from $A$. solani could also be differentiated from the specific values of $P$. fuligena rDNA by a lower $\mathrm{Tm}$ value $\left(\mathrm{Tm} 83.6^{\circ} \mathrm{C}\right)$. This detection specificity in combination with the high efficiency of the qITSpf primer pair qualified its application for the analysis of the whole IL population using the optimized conditions determined during the specificity tests.

Relationship between the visual phenotyping and the qPCR results. An important quality feature for a newly developed molecular pathogen test is its general correlation with visually observed symptoms. Ideally, an assay should verify the visual symptoms in a more exact quantitative way to eliminate subjective systematic bias. In this study, we compared the correlation of visual phenotyping and qPCR data of (i) a complete IL library under natural infection conditions in Thailand and (ii) a subpopulation of ILs after artificial inoculation in a growth chamber. The correlation between the transformed data from the visual phenotyping and the detected amounts of fungal DNA were tested using a Pearson's product-moment correlation (Fig. 3A). The fungal DNA amount and the visual phenotyping were significantly correlated but the regression explained only $39 \%$ of the relationship. After inoculation with the $P$. fuligena isolate, the visual phenotyping observa-

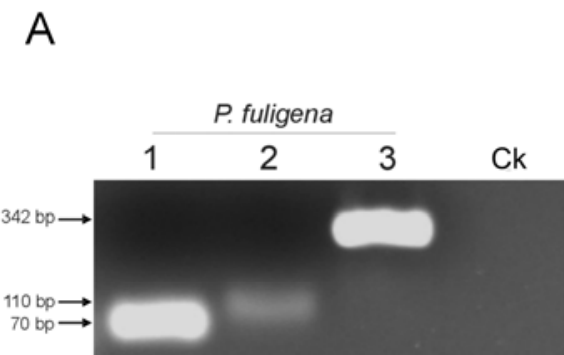

B
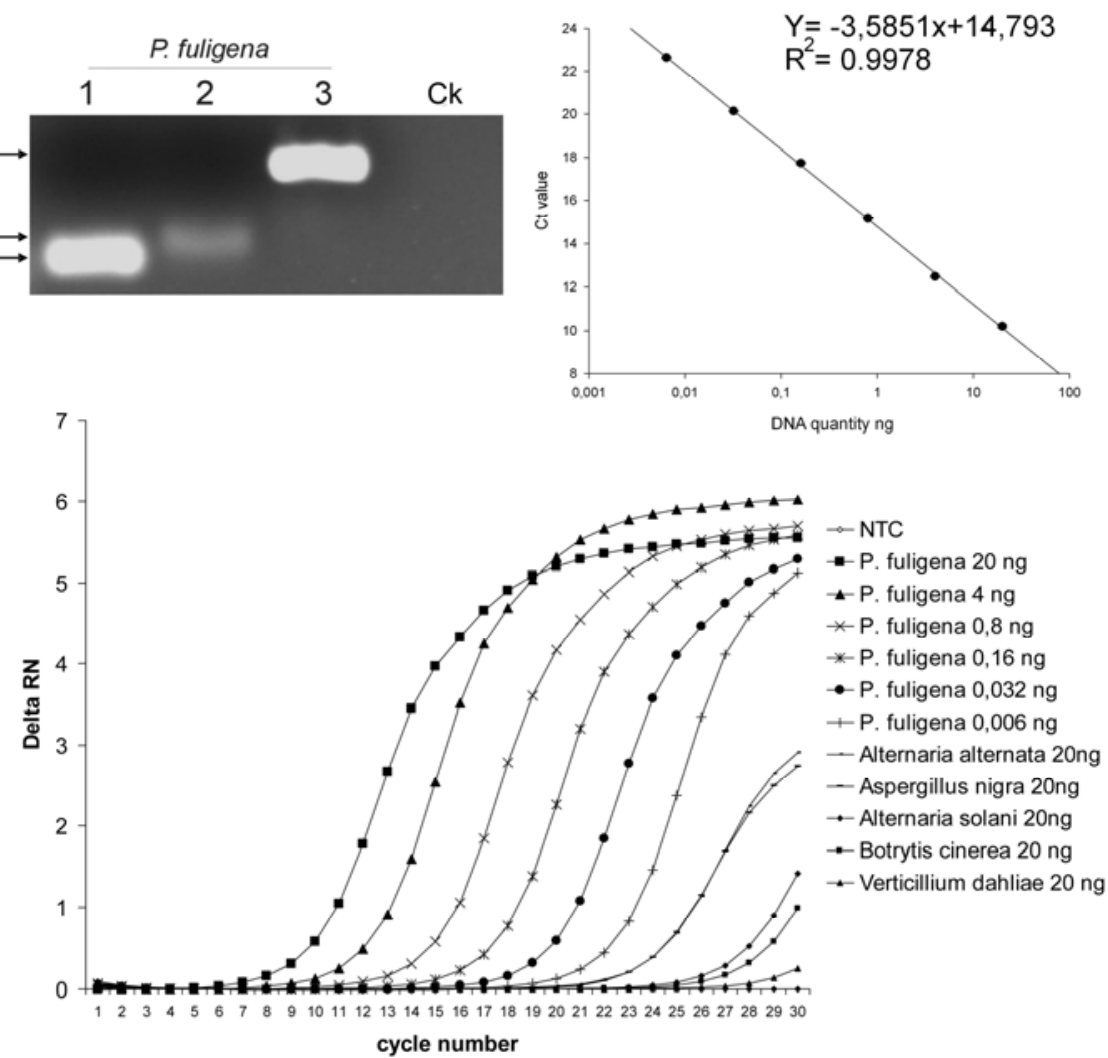

Fig. 4. Specificity and sensitivity of designed primer pairs. A, Specific amplification of Pseudocercospora fuligena ribosomal DNA using the primer pairs internal transcribed spacer (ITS)1 (1), ITS2 (2), and qITSpf (3) in a conventional polymerase chain reaction (PCR). Arrows indicate the specific fragment sizes. PCR was performed using $25 \mathrm{ng}$ of genomic DNA from $P$. fuligena. In the negative control (Ck), DNA was replaced by water. B, Standard curve showing cycle threshold values plotted against the known amounts of $P$. fuligena genomic DNA using the qITSpf primer pair (average of three replicates \pm standard deviation). Fungal genomic DNA was serially diluted to yield final amounts ranging from $6 \mathrm{pg}$ to $20 \mathrm{ng}$. The regression line equation and the $R^{2}$ value are displayed; ${ }^{* *}$ denotes probability level at $P<0.001$. C, Test for cross-reaction with other fungal pathogens on tomato in the SYBR-Green qPCR assay for $P$. fuligena using the qITSpf primer pair. Assays were performed using a dilution series of genomic DNA from P. fuligena and $20 \mathrm{ng}$ of genomic DNA template from Alternaria alternata, Aspergillus nigra, Alternaria solani, Botrytis cinerea, and Verticillium dahliae isolates. Values represent means of $n=3$ technical replications. In the negative control (NTC), DNA was replaced by water. The delta Rn value is the fluorescent signal normalized to the passive reference dye ROX (Applied Biosystems, Carlsbad, CA) and minus the baseline signal. 
tions and fungal DNA amounts were significantly correlated and the regression analysis explained $87 \%$ of the relationship (Fig. 3C). Tomato lines without visual symptoms (LA3919, LA3999, and LA3920) had DNA amounts lower than 1 pg per $100 \mathrm{ng}$ of total DNA, like the resistant donor (LA1777). The tomato lines LA3928 and LA3932, with mild symptoms, had about three times lower DNA amounts compared with the RP (LA4024). The highly susceptible line LA3940 showed a four times elevated DNA amount compared with the RP. There was a trend to underrate the BLM infection based on visual phenotyping in lines with high fungal DNA amounts and to overrate the BLM infection based on visual phenotyping in lines with low fungal DNA amounts (Fig. 3B).

All introgressions are defined by flanking markers (TomatoEXPEN map; 28) and traits conferred through introgressed segments can be linked to chromosomal areas by this existing genetic map. Relating the phenotyping with the map of the chromosomal location of the introgressions (14) revealed that the P. fuligenaresistant ILs (LA3919, LA3999, and LA3920) share an overlapping introgression on chromosome one located on the interval CT233-TG184 (0 to 20 centimorgans). The $P$. fuligena mediumresistant lines (LA3928 and LA3932) possess introgressions on chromosomes three, four, and eight while the highly susceptible line LA3940 has an introgression on chromosome five.

\section{Discussion}

Accurate phenotyping is essential for plant-disease resistancebreeding. If the rating of disease symptoms is incorrect, individuals carrying resistance genes from a mapping population might not be identified. Missing them inhibits the development of reliable markers suited for the identification of these resistance genes and for marker-assisted selection. In order to accomplish reliable identification of $P$. fuligena-resistant ILs from an IL library, a qPCR assay was developed. The qPCR method is an appropriate tool for species-specific detection of fungi in plant material (26). This sequence-based identification procedure requires primers which amplify the ITS of the fungal rDNA. Due to their high variability, these sequences are capable and useful in distinguishing between fungal species (45) and allow even isolate-specific detection (44). The absolute quantification with qPCR has been shown to be a reproducible and sensitive method to quantify the abundance of a specific fungal rDNA sequences $(20,23)$, and is well suited for low titers and high-throughput analyses (29).

In a basic research-orientated approach, the pathogen response of Arabidopsis thaliana infected by Alternaria brassicicola and $B$. cinerea was described by SYBR Green-based qPCR assays (15). In a similar, breeding-orientated approach, Jackson et al. (20) compared digital image analysis with visual phenotyping of a fungal infection in the host plant to a qPCR assay for evaluation of resistance to oat crown rust. Data generated by qPCR permitted higherresolution identification of a QTL than visual and digital assessments. Our study results confirm the high sensitivity of the qPCR assay in facilitating a clear separation of $P$. fuligena-resistant lines showing no or low fungal colonization without or with weak expression of visual symptoms and highly susceptible lines (Fig. 4C).

A qPCR assay, using the intercalating SYBR Green dye, has been developed for the detection of $P$. fuligena in tomato leaves. The qPCR is a fast and highly sensitive technical solution $(23,31)$ and the SYBR Green chemistry is an appropriate tool to quantify fungal pathogens in infected plant material. Whether the SYBR Green chemistry is a suitable method to quantify fungal pathogens in infected plant material or whether the TaqMan technology should be preferred for this field is a broadly discussed topic in current literature $(8,42)$. Many published qPCR assays for detection of fungi in plant material use TaqMan technology $(25,38)$ and legitimatize the use of this cost-expensive technique because of the unspecific binding of the intercalating fluorescence dye SYBR Green. The results presented here clearly demonstrate that it is possible to discriminate between the infection levels of P. fuligenainfected tomato leaves with a SYBR Green-based qPCR assay. The specificity of PCR primers in SYBR Green-based assays deter- mined by sequence alignments is a key for the development of high-quality tests. In the present experiment, a number of heterologous areas within the fungal ITS regions were used to develop specific primer pairs. The results of the specificity tests (Fig. 4A, $\mathrm{B}$, and $\mathrm{C}$ ) reflect a reproducible and highly specific assay with a detection limit as low as $6 \mathrm{pg}$ by using the specifically developed primers in combination with the SYBR Green dye. This technique reached a quality and sensitivity comparable with that described for the detection of rDNA with TaqMan probes (10). It can be concluded that the SYBR Green assay is a flexible and low-cost technique (7). This fact makes it more flexible for research approaches compared with the cost-intensive TaqMan technique.

For accurate identification of introgression-mediated traits from the donor, an exact phenotyping of lines of an IL population is a prerequisite. The integrative use of detailed visual phenotyping observations supported by $\mathrm{qPCR}$ assay quantification results to identify introgressions conferring resistance against $P$. fuligena clearly demonstrates the potential of such an approach in the identification of QTLs and, possibly, the underlying genes. Because the qPCR assay reliably quantified the colonization of leaves by $P$. fuliginea, close correlation between the fungal rDNA content of the leaves and the visual rating of BLM severity for the entire IL library could be expected. Under natural infection conditions in Thailand, a significant correlation could be demonstrated. However, the regression explained only $39 \%$ of the relationship, with major deviations from the regression line (Fig. 4A). The loose correlation in the nethouse experiment in Thailand could be explained by mainly three reasons. (i) The visual rating of BLM infestations might have been biased by infections with other fungal pathogens or by the formation of necrotic spots as a response of the donor and some ILs to heat stress, giving rise to rating inaccuracies or masking BLM symptoms. (ii) The ITS of P. fuligena could be variable in the native population in Thailand. For this reason, it is unlikely because the used isolate was isolated in the nethouses in Thailand and three other isolates from the experimental site in Thailand showed no variability in the ITS sequence. (iii) The quantification of fungal DNA using qPCR might not have been fully reliable. Leaves of BLM-susceptible ILs for DNA analysis formed dry, necrotic lesions at the advanced stage of sampling in Thailand. In DNA samples isolated from partially necrotic leaves or woody plant tissues, the presence of strongly inhibitory substances is a frequent problem for PCR-based systems used to detect plant pathogens in hosts (22). Despite widely applicable plant DNA extraction procedures such as the CTAB method used here, inhibition is also a problem in many routine applications, compromising the assay sensitivity and reliability $(5,30)$. Secondary plant metabolites such as polyphenols and other phenolic compounds are known to be PCR-inhibitory contaminants for DNA extracts from necrotic plant material. Another explanation for a lower detection level with qPCR in severely diseased leaves could be a degradation of target molecules in the necrotic areas or a different sensitivity of single ILs against $P$. fuligena. The inability to discriminate between living and dead fungal material with molecular methods is the reason why classical visual observations are still mandatory for selecting resistant plants $(38,39)$.

In growth-chamber experiments, a significantly higher correlation could be demonstrated. The regression explained $87 \%$ of the relationship with major deviations from the regression line (Fig. 4C). The fact that, in the growth-chamber experiment, the visual rating and the sampling for DNA analysis were done at an earlier stage, when BLM expressed defined lesions without necrotic areas, supports the hypothesis that necrotic areas inhibit the DNA isolation or lead to a degradation of DNA in the necrotic leaf areas. A difference between the growth-chamber experiments in Germany and nethouse experiments in Thailand is the mode of inoculation. Under natural inoculation in Thailand, spores were the main inoculum whereas, in growth-chamber experiments in Germany, mycelium was used for spray inoculation. However, independent of the inoculation technique and the environmental conditions, the resistant and the sensitive ILs were consistently classified under both 
experimental conditions. This strongly suggests that the resistance mechanism is inoculation-technique independent.

All three of the highly resistant tomato lines share an introgression on chromosome one (28). Based on these findings, a resistance-mediating effect is located on an overlapping interval between the marker CT233 and TG184 (Tomato-EXPEN map; 14). The origin of the resistance against $P$. fuligena is clearly defined in the interval on chromosome one but it cannot be decided whether the described interval carries a single resistance gene or a cluster of relevant genes.

The identification of an introgression conferring $P$. fuligena resistance represents a potential opportunity to fine map the relevant interval, which could allow marker-assisted selection for BLM resistance breeding. Furthermore, present efforts linking the genomic information of these introgressions to the differences between the RP and the resistant ILs in the transcriptome, proteome, and metabolome is expected to facilitate pinpointing genes and metabolic pathways related to BLM resistance and tolerance.

\section{Acknowledgments}

We thank the Tomato Genetics Resource Center, Davis, CA, for the supply of the seed of the ILs and the parents; the German Research Foundation (DFG) Research Group FOR 431 "Protected cultivation-an approach to sustainable vegetable production in the humid tropics" for financial support for the phenotyping of the genotypes at AIT, Thailand and V. M. Salokhe, AIT, for support.

\section{Literature Cited}

1. Arya, L. M., Pulver, E. L., and van Genuchten, M. T. 2000. Economic, environmental, and natural resource benefits of plastic shelters in vegetable production in a humid tropical environment. J. Sustain. Agric. 17:123-143.

2. Ayele, Z. M. 2008. Epidemiological Investigations of Black Leaf Mold. (Pseudocercospora fuligena (Roldan) Deighton) on tomato (Solanum lycopersicum L.) under protected cultivation. Ph.D. thesis. Leibniz University, Germany.

3. Baxter, C. J., Sabar, M., Quick, W. P., and Sweetlove, L. J. 2005. Comparison of changes in fruit gene expression in tomato introgression lines provides evidence of genome-wide transcriptional changes and reveals links to mapped QTLs and described traits. J. Exp. Bot. 56:1591-1604.

4. Beaumont, A. 1954. Tomato leave mould: Spraying trials in Lancashire and Yorkshire. Plant Pathol. 3:21-25.

5. Bickley, J., and Hopkins, D. 1999. Inhibitors and enhancers of PCR. Pages 81-102 in: Analytical Molecular Biology Quality and Validation, Suppl. 190. G. C. Saunders and H. C. Parkes, eds. Redwood Books Ltd., Wiltshire, UK.

6. Bockus, W. W., Su, Z., Garrett, K. A., Gill, B. S., Stack, J. P., Fritz, A. K., Roozeboom, K. L., and Martin, T. J. 2007 .Number of experiments needed to determine wheat disease phenotypes for four wheat diseases. Plant Dis. 91:103-108.

7. Brandfass, C., and Karlovsky, P. 2008. Upscaled CTAB-Based DNA extraction and real-rime PCR assays for Fusarium culmorum and F. graminearum DNA in plant material with reduced sampling error. Int. J. Mol. Sci. 9:23062321.

8. Burlakoti, R. R., Estrada, R., Rivera, V. V., Boddeda, A., Secor, G. A., and Adhikari, T. B. 2007. Real-time PCR quantification and mycotoxin production of Fusarium graminearum in wheat inoculated with isolates collected from potato, sugar beet, and wheat. Phytopathology 97:835-841.

9. Canady, M. A., Meglic, V., and Chetelat, R. T. 2005. A library of Solanum lycopersicoides introgression lines in cultivated tomato. Genome 48:685-697.

10. Cao, A. X., Liu, X. Z., Zhu, S. F., and Lu, B. S. 2005. Detection of the pinewood nematode, Bursaphelenchus xylophilus, using a real-time polymerase chain reaction assay. Phytopathology 95:566-571.

11. Dudoit, S., and van der Laan, M. 2008. Multiple Testing Procedures with Applications to Genomics. Springer, Berlin.

12. Eshed, Y., and Zamir, D. 1994. A genomic library of Lycopersicon pennellii in L. esculentum: A tool for fine mapping of genes. Euphytica 79:175-179.

13. Francis, D. M., Kabelka, E., Bell, J., Franchino, B., and St. Clair, D. 2001 Resistance to bacterial canker in tomato (Lycopersicon hirsutum LA407) and its progeny derived from crosses to L. esculentum. Plant Dis. 85:1171-1176.

14. Fulton, T., van der Hoeven, R., Eannetta, N., and Tanksley, S. 2002. Identification, analysis and utilization of a conserved ortholog set (COS) markers for comparative genomics in higher plants. Plant Cell 14:1457-1467.

15. Gachon, C., and Saindrean, P. 2004. Real-time PCR monitoring of fungal development in Arabidopsis thaliana infected by Alternaria brassicicola and Botrytis cinerea. Plant Physiol. Biochem. 42:367-371.

16. Hartman, G. L., Chen, S. C., and Wang, T. C. 1991. Cultural studies and pathogenicity of Pseudocercospora fuligena, the causal agent of black leaf mold of tomato. Plant Dis. 75:1060-1063.

17. Hartman, G. L., and Wang, T. C. 1992. Black leaf mold development and its effect on tomato yield. Plant Dis. 76:462-464

18. Hartman, G. L., and Wang, T. C. 1993 Resistance in Lycopersicon species to black leaf mold caused by Pseudocercospora fuligena.
Euphytica 71:125-130.

19. Inoue, H., Nojima, H., and Okayama, H. 1990. High efficiency transformation of Escherichia coli with plasmids. Gene 96:23-28.

20. Jackson, E. W., Obert, D. E., Menz, M., Hu, G., Avant, J. B., Chong, J., and Bonman, J. M. 2007. Characterization and mapping of oat crown rust resistance genes using three assessment methods. Phytopathology 97:1063-1070.

21. Kesel, A. B., Junge, M. M., and Nachtigall, W. 1999. Einführung in die angewandte Statistik für Biowissenschaftler. 1. Edit. Birkhäuser Verlag, Basel, Switzerland.

22. Langrell, S. R. H., and Barbara, D. J. 2001. Magnetic capture hybridisation for improved PCR detection of Nectria galligena from lignified apple extracts. Plant Mol. Biol. Rep. 19:5-11.

23. Lees, A. K., Cullen, D. W., Sullivan, L., and Nicolson, M. J. 2002. Development of conventional and quantitative real-time PCR assays for the detection and identification of Rhizoctonia solani AG-3 in potato and soil. Plant Pathol. 51:293-302.

24. Littell, R. C., Milliken, G. A., Stroup, W. W., and Wolfinger, R. D. 1996. SAS System for Mixed Models. SAS Institute Inc. Cary, NC.

25. Mackay, I. M., Arden, K. E., and Nitsche, A. 2002. Real-time PCR virology. Nucleic Acids Res. 30:1292-1305.

26. Martin, K. J., and Rygiewicz, P. T. 2005. Fungal-specific PCR primers developed for analysis of the ITS region of environmental DNA extracts. BMC Microbiol. 5:28.

27. Max, J. F. J., Horst, W. J., Mutwiwa, U. N., and Tantau, H.-J. 2009. Effects of greenhouse cooling method on growth, fruit yield and quality of tomato (Solanum lycopersicum L.) in a tropical climate. Sci. Hortic. 122:179-186.

28. Monforte, A. J., and Tanksley, S. D. 2000. Development of a set of near isogenic and backcross recombinant inbred lines containing most of the $L y$ copersicon hirsutum genome in a $L$. esculentum genetic background: a tool for gene mapping and gene discovery. Genome 43:803-813.

29. Mumford, R. A., Boonham, N., Tomlinson, J., and Barker, I. 2006. Advances in molecular phytodiagnostics-new solutions for old problems. Eur. J. Plant Pathol. 116:1-19.

30. Murray, M. G., and Thompson, W. F. 1980. Rapid isolation of high molecular weight plant DNA. Nucleic Acid Res. 8:4321-4325.

31. Nicholson, P., Rezanoor, H. N., Simpson, D. R., and Joyce, D. 1997. Differentiation and quantification of the cereal eyespot fungi Tapesia yallundae and Tapesia acuformis using a PCR assay. Plant Pathol. 46:842-856.

32. Nita, M., Ellis, M. A., and Madden, L. V. 2003 Reliability and accuracy of visual estimation of Phomopsis leaf blight of strawberry. Phytopathology 93:995-1005

33. Nutter, F. W., Jr., Gleason, M. L., Jenco, J. H., and Christians, N. L. 1993. Accuracy, intra-rater repeatability, and inter-rater reliability of disease assessment systems. Phytopathology 83:806-812.

34. Nutter, F. W., Jr., and Schultz, P. M. 1995. Improving the accuracy and perception of disease assessments: selection of methods and use of computer-aided training programs. Can. J. Plant Pathol. 17:174-184

35. Piepho, H.-P., Büchse, A., and Emrich, K. 2003. A hitchhiker's guide to mixed models for randomized experiments. J. Agron. Crop Sci. 189:310-322.

36. Roldan, E. F. 1938. New or noteworthy lower fungi of the Philippine Islands, II. Philipp. J. Sci. 66:7-17.

37. Rozen, S., and Skaletsky, H. J. 2000. Primer3 on the WWW for general users and for biologist programmers. Pages 365-386 in: Bioinformatics Methods and Protocols: Methods in Molecular Biology. S. Krawetz and S. Misener, eds. Humana Press, Totowa, NJ.

38. Schena, L., Hughes, K. J. D., and Cooke, D. E. L. 2006. Detection and quantification of Phytophthora ramorum, $P$. kernoviae, $P$. citricola, and $P$. quercina in symptomatic leaves by multiplex real-time PCR. Mol. Plant Pathol. 7:365-379.

39. Schena, L., Nigro, F., Ippolito, A., and Gallitelli, D. 2004. Real-time quantitative PCR: a new technology to detect and study phytopathogenic and antagonistic fungi. Eur. J. Plant Pathol. 110:893-908.

40. Turner, A. S., Nicholson, P., Edwards, S. G., Bateman, G. L., Morgan, L. W., Todd, A. D., Parry, D. W., Marshall, J., and Nuttall, M. 2001 Evaluation of diagnostic and quantitative PCR for the identification and severity assessment of eyespot and sharp eyespot in winter wheat. Plant Pathol. 50:463-469.

41. Turner, A. S., O'Hara, R. B., Rezanoor, H. N., Nuttall, M., Smith, J. N., and Nicholson, P. 1999 Visual disease and PCR assessment of stem base diseases in winter wheat. Plant Pathol. 48:742-748.

42. Walsh, K., Korimbocus, J., Boohham, N., Jennings, P., and Hims, M. 2005. Using real-time PCR to discriminate and quantify the closely related wheat pathogens Oculimacula yallundae and Oculimacula acuformis. J. Phytopathol. 153:715-721.

43. Wang, T. C., Black, L. L., Hsieh, W. H., and Hanson, P. M. 1992. Inheritance of black leaf mold resistance in tomato. Euphytica 86:111-115.

44. Ward, E., Foster, S. J., Fraaije, B. A., and McCartney, H. A. 2004. Plant Pathogen diagnostics: immunological and nucleic acid-based approaches. Ann. Appl. Biol. 145:1-16.

45. White, T. J., Bruns, T. D., Lee, S., and Taylor, J. 1990. Amplification and direct sequencing of fungal ribosomal genes for phylogenetics. Pages 315 322 in: PCR Protocols. M. A. Innis, D. H. Gelfrand, J. J. Sninsky, and T. J. White, eds. Academic Press, San Diego, CA.

46. Zamir, D. 2001. Improving plant breeding with exotic genetic libraries. Nat. Rev. Genet. 2:983-989. 